did not contmet well, as considerable hrmorthe uterus did not contract well, as considerable hømorrhage occurred immediately after. The pulse, while the patient remained unconscious after the convulsious, was stow and just perceptible, gradually regaining in about twenty or twenty-five minutes after; but, probably owing to the homorrhage, remained weak. Consciousness appeared to be returning, when a secend Consciousness appeared the same kind as the last, but longer in passing off, occurred, followed by the same comatose state as before. This time consciousness never returned up to the next attack of conpulsions. As hæmorrhage had been going on prett5 freely all this time, the uterus alternately contracting and dilating, and expelling a quantity of blood each time, I judged that depletion had gone far enough, and endearoured by pressure, cold, etc., to produce permanent uterine contraction. This was not an easy permanent uterine during the convulsions, which soon recurred, as she tossed about violently; but ultimately, I succeeded by pressure of the hand in causing a pretty firm contraction, though there was still a slight discharge of blood.

About 3, or between 3 and 4 A.M., Mr. C., for whom a messenger had been dispatched at the first occurrence of the convulsions, arrived. He seemed to think that hæmorrhage had gone quite far enough; and as there was still a slight discharge from the uterus, and this viscus was rather large; he passed his hand into it, and extracted some clots, after which the pressure of a bandage caused it to contract firmly. There had been previously cold applied to the head, and a sinapism between the shoulders.

Mrs. R. now had sinapisms applied to the head and calves of the legs. The convulsions after this several times recurred up to 8 P.M., when the patient lay unconscious; skin cold and clammy, pupils dilated and insensible, breathing stertorous, pulse as nearly as possible imperceptible, power of swallowing suspended. She remained in this state for some time, but then gradually reaction crept on, warmth became slowly restored to the surface, and the power of swallowing returned. Advantage was taken of this to administer a stimulating draught, composed of some spirit of ammonia and spirit of lavender, which Mr. C. happened to have with him. This had the effect of making her vomit the medicine itself, and with it some partly digested fish, which it seemed she had eaten the previous day. Reaction now proceeded slowly; but it was afternoon before she could answer questions collectedly, and had entirely regained consciousness. There was no returu of the convulsions; and she convalesced without any unfavourable symptoms, save irritation of the lower extremities, and considerable oedema of the face and head, apparently owing to the sinapisms, which had been left on for too long a time. It was some weeks before she had regained strength sufficiently to sit up.

The friends of the patient having been privately informed by some member of the profession, who, no doubt, was influenced by the most benevolent motives, that the case was wrongly treated, inasmuch as venesection should have been performed, and was not-I refrain from any remarks, and content myself with stating the facts as they occurred, of which the profession in general must judge.

\section{CASE OF EXTRA-UTERINE PREGNANCY.}

By PYE H. CHAVASSE, F.I.C.S., late President of Queen's College Medico-Chirur rical Society, Birmingham.

[Read before the Socicty in the Spring of 1853.]

LasT year I had a case of cxtra-uterine pregnancy; and as it contains many points of interest, I have much pleasure in bringing it before your notice. Before making any further remarks on the subject, I will, if you please, give the history of the case, which I have copied almost verbatim from my note-book.

On January lst, 1852, I was sent for to Mrs. H. She is 39 jears of age; has had several children, but has only one child living. Sometime in the beginning of August 1851, child living. Some suddenly out Thile passing the Malding, and, by accident, struck her a violent blow of the building, and, by accident, struck her a violont be was on the abdomen with a basket of potatoes, which he was carrying. She immediately fainted, and, on recovering from the syncope, she complained of great pain of the part which had been struck, and felt very ill. Soon after, she was seized with a violent peritonitis. The medical mnn in attendance treated her very actively; he ordered, at difierent times, sixty leeches to the abdomen, and salivated her. Under this treatment, the symptoms of peritonitis ceased; but still the patient continued very ill.

The first medical man (a physician) gave up the case to general practitioner, who was puzzled, as he well might and could not make out the nature of the complaint.

Her sufferings at this time, both day and night, were Her sufferings at this time, both day an proof of which, me declared that, in one day, she took six powerful composing draughts, and without deriving any relief. She had posing draughts, and without deriving any rell number; but instead of getting better, she became rapidly worse. Her sufferings had so reduced her, that she was more like a skeleton than a living woman.

On January lst, 1852, I saw her for the first time. On careful examination, I found a large tumour midway between the superior fortion of the hypogastric and the inferior portion of the umbilical region, rather inclining to the right iliac, and assuming somewhat the shape of a the right iliac, and assuming somewhat the shape could gravid uterus; it was hard and immovable, and 1 could not detect fluctuation, or, or that time, fobe umbilicus, had given way for several inches in extent, and had allowed a given way for several the bowels. This ventral hernia was large protrusion of the bowels. This ventral hernia was distended with flatus. The bowels were completely loaded with fæcal matter. She was not able to make water withwith frcal matter. had not menstruated since the accident in August. Some months before I was called in, she had had a very copious and long continued purulent discharge, but which had entirely ceased upon my arrival.

The examination, per vaginam, threw but little light on the case. There was a large substance of some kind nearly blocking up the pelvis, but of what nature, I could not decide. The vagina was pushed out of its proper course, instead of being "oblique from below upwards and backwards, and its axis corresponding with that of the outlet of the pelvis", the posterior wall of the ragina was pushed forwards, the anterior wall was drawn directly upwards behind the pubes, and narrowed like a funnel. The os uteri was too high up to be felt; otherwise, probably, it would be found looking towards the upper part of the os pubis.

The impression upon my mind, on first seeing the case, was, that she had an ovarian tumour, attended with engorged fæcal state of the bowels. Indeed, the bowels were so loaded, that they were as hard as a board, and the peristaltic action, in consequence, could scarcely be performed. My first duty, therefore, was to thorouginly clear out the bowels. This I did, and with the happiest effect. She became a new woman; her appetite, her strength, her sleep, her spirits, all returned, and she quite made up her mind that she should recover.

After I had been in attendance upon her for six weeks or two months, that is to say, towards the end of February (and five months after the accident) strong symptoms of pregnancy showed themselves; her breasts enlarged; there was a dark areola around the nipple; milk in quantities (containing milk globules) could be squeezed out of them; the tumour of the abdomen gradually increased in size, and extended more anteriorly, and motion was felt in it. The stethoscope, too, now decidedly told of a fœital circulation. With these decisive symptoms, all doubts of its being anything but pregnancy vanished; especially, as the tumour came more in front, and assumed more the shape of a gravid uterus. 
Dot ofill, the ase wes most extraondinary; there vere thes swellings distinctly to be folt, the one below, in the hroonetrium, and just above the symphysis pubis, very man, and of the size of a large cricket ball; another in the middle, in the umbilical region (which afterwards turned out to be the extra-nterine pregnancy); and a third, which was in front, and was mid way between the epigastric and umbilical regions, rather above the last mentioned, and which was the hernia protruding through the linea alba.

About the middle of March, a violent attack of bronchitis came on, which terribly reduced her strength. Again she became excessively thin.

About three wreeks before she died, she sent for me in the night, considering herself to be in labour, which opinion appeared to be confirmed by her having a regular " show", guite as much as she would have in a natural labour. She had pains like labour pains, at first "grinding", and then assuming a bearing-down character. The abdomen was eridently much smaller. She did not now feel the motion of the child.

On making an examination, per vaginam, I could not find or trace the os uteri. The vagina was pushed out of its place, and continued to assume the direction I before mentioned, that is to say, there was a passage anteriorly, leading to a cul-de-sac, like to the finger of a glove; posteriorly, I could not trace any passage. There was a large tumour at the brim of the pelvis, very much like the head of a child, with some substance between, which I could not make out.

The case was so exceedingly obscure and puzzling, that I was determined to have the opinion of $m y$ friend Mr. Berry. He immediately responded to $\mathrm{my}$ call, and thoroughly investigated the case. Mr. Berry has kindly favoured me with the following written remarks of the examination of the patient, per vaginam, and otherwise. They are as follows: "When called to the interesting case, through the kindness of Mr. Pye Chavasse, after carefully examining the abdomen, I found a large tumour in the right hypochondrium, extending up to the umbilicus on that side; it was firm, smooth, and its outline well defined; and gave me the impression of a large ovarian cyst. There was no foetal movement, no sound could be heard by the stethoscope. Upon making a raginal examination, the same swelling as indicated by the finger in the vagina and the hand externally upon the abdomen, lay deep in the pelvis, filling its cavity, and altering the course of the vagina, which passed directly upwards, behind the symphysis pubis; it was painful to the touch, and a slight red discharge passed from the vagina. The uterus could not be felt, nor could the finger reach the upper extremity of the elongated ragina."

The poor creature's strength rapidly gave way. She made me promise that we would open her as soon as she was dead. This, of course, I was very happy to do, in order to clear up the mpstery that enshrouded the case.

She died April 17th, 1852, and on the Sunday following Mr. White, in the presence of Mr. Berry and myself, opened her. On exposing the abdominal viscera, we found that she had had most extensive inflammation. Some parts of the bowels were nearly black, and extensive adhesions had taken place. The uterus was perfectly healthy, and unimpregnated, but rather larger than ordinary. It was pushed somewhat out of its proper position; the os uteri, instead of being in its usual place, was looking forwards, facing the upper part of the symphysis pubis. This circumstance proves the utterimpossibility of our tracing the os uteri. It was, in fact, completely, and for some distance, out of the reach of the longest finger. But now came the most wonderful and interesting post mortem appearance I ever witnessed, or, perhaps, ever shall witness again. The Fallopian tube of the right side was hypertrophied to an enormons size-to the size of a gravid uterus of eight months. On opening the tube, there was a perfectly formed healthy child, as largeas many children at the full time, and weighing rearly seven pounds, with a placenta adherent to the posterior and inferior part of the tube. Indeed, the Fallopian

\section{appeared to have put on the structure, appearnnce, and} functions of the uterus. The right ovary could not be found; it seemed to have been absorbed in the immenso tumour.

Mr. White kindly undertook to preserre the preparation, which he has done carefully and well. Unfortunately, the child could not be preserved; it was too far gone, or it would have added much to the interest of the preparation. The preparation is now the property of the Queen's College Museum, Birmingham.

I think that I do not overrate the case when I say, that I consider it to be full of interest, and, with your permission, I will take a rapid survey of it.

Dr. Granville, in his graphic work on Abortion, asserts that there are four species of erratic gestation; namely, gestatio ovaria, gestatio tubica, gestatio interstitialis, gestatio abdominalis. According to Velpeau, ovarian gestation never occurs. He asserts, " that when once the ovum is vivified, it has never yet been found inclosed in the envelope of this organ, as in a cyst."

of intersticial pregnancy-that is to say, the orum lodging in the very substance of the fleshy structure of the uterus-Dr. Granville, in his work on Abortion, gives a most beautiful specimen. This species is exceedingly rare.

of abdominal or peritoneal pregnancy, several cases are on record. In one case, where the foctus was found loose in the abdomen; in another case, where the cord was inserted in the mesentery; in a third, where the placenta was attached in front of the spine; in a fourth, where the pla centa was attached to the kidneys and intestines. Many other cases have been mentioned by Velpeau.

But, of all species of erratic gestation, the tubal is the most frequent, in the proportion (according to Velpeau) as nine to three.

In my case, did the frightful pain arise, in a great measure, from the stretching of the Fallopian tube? We all know the pain patients experience while passing gallstones, from the stretching of the duct alone. If you recollect, I mentioned that my patient could not make water unless she pressed the bladder downwards. This arose from the misplacement of the urethra. The urethra was pressing against the symphysis pubis.

With regard to the milk in the breasts containing milk-globules: this turned out to be one of the most conclusive signs of her pregnancy.

The cause of extra-uterine pregnancy is generally said to be moral. It is a singular fact, that more single women labour under erratic gestation than married. This is thought by Velpeau and others to arise, at the time of connexion, from sudden fear of the consequences, or from fright at being disturbed during the very act. Thus, "Lallemand, in one case, attributed the accident to a fright or start at the moment of conception."

In my patient, the tubal pregnancy could be traced to physical force-to the accident alone. It strikes me that the ovum must have been resting in or passing along the tube at the time of the accident. The blow caused at first a spasm of the tube (the tube being muscular): afterwards, inflammation followed, which probably blocked up the end of the Fallopian tube nearest to the uterus, thus preventing the passage of the fotus into the womb. It is, I believe, well ascertained that the ovum is generally vivified by the spermatozoa in the Fallopian tube, although this vivification occasionally takes place at the surface of the ovary. Such being the case, may not the ovum remain sometime in the tubc. while vivification was taking place, and while preparation for the membrana decidua and other matters were going on in the uterus. If my reasouing be correct, we can readily understand why the ovum was in the Fallopian tube, and not in the uterus, at the time of the accident.

The diagnosis in this case was most difficult. Decided symptoms of pregnancy did not occur until towards the end of February. The violent peritonitis at first; the utter impossibility of reaching the os uteri; the discharge of pus from the vagina; the choked-up state of the bewels; 
the throe distinct swellings, namely, the hernia above, the extre-foetal pregnancy in the middle, and the misplaced uterus below ; the violent spasms of the Fallopian tube,all masked the disease, and formed obstacles to a correct diagnosis.

Dr. Robert Lee, in his valuable Lectures, gires an interesting case of tubal pregnancy, which in some respects resembles my own. He says:- "The following case, which is the last I have seen of the sort, may serve to illustrate the difficulty of the diagnosis, and the impossibility of rendering any assistance by art where no effort is made by nature to establish an opening in the abdominal parietes through which the fotus may escape." Dr. Lee then gives the history of the case; but I will only touch upon those symptoms which were somewhat similar to my own patient's. “The cavity of the pelvis was occupied by a hard immovable mass, and the os uteri was forced up by this behind the symphysis pubis, so high that it could scarcely be touched." In my case, the os uteri could not be reached. "She died in December 1841; and, on opening the abdomen, we found", says Dr. Lee, "a large mass, like the gravid uterus in the seventh month, occupying the whole of the hypogastrium." The worthy doctor goes on to state "that the walls of the uterus were healthy, and the cavity empty." The great difference between this case and the one I have had the honour of bringing before the Society is this, that, in the former case, "the ovaria and tubes could not be distinctly seen in the confused mass; and he (Dr. Lee) was unable to determine whether it was a case of ventral or tubal gestation? While in my case, although the ovaria could not be traced, the Fallopian tube was 28 visible as a gravid uterus at the full period of gestation.

The prognosis in extra-uterine pregnancy, more especially of the Fallopian tube, is generally-indeed, in the latter always - to be regarded as unfavourable. In abdominal pregnancy, several cases are recorded of recovery; one case mentioned by Velpeau, who lived to the age of between 70 and 80 . The extra-uterine fotus had become petrified. Another case is recorded, where ulceration had taken place of the bowels, and the fotus and appendages had passed through them: another, where an opening by ulceration had been made in the groin, and the fœtus had come away piecemeal. Other extraordinary cases are recorded, which I will not weary you by detailing. Almost invariably tubal pregnancy is fatal at an early period; although "there is," says Dr. Burn, " in the Museum of the College of Surgeons, Dublin, a preparation of tubal pregnancy which had existed twenty years. The placenta and decidua are seen within the tube or sac; and the child, of the ordinary size at the ninth month, is perfect, as if it had been kept in spirits." Ir. Robert Lec states, that women labouring under tubal pregnancy seldom reach the fifth month, and that they generally die of internal hæmorrhage a few hours after the rupture of the tube. "In 1830," says Dr. Lee, "I saw three examples of tubal gestation, in all of which death speedily ensued from the same cause." Velpeau also asserts that extra-uterine pregnancy commonly terminates before the fifth month. Martin, Turnbull, and some others, have nevertheless seen it much more prolonged, and cren to the term of ordinary gestation. It is well worthy of notice, that, although my patient had had so violent an inflammation of the peritoneum, and that the Fallopian tube had been, of course, injured and weakened by the blow, still, under all these disadvantages, the pregnancy had continued; the child living and thriving in his extraordinary dwelling-place for eight months, and without bursting the Fallopian tubc. Velpeau declares "that it is rare for the fotus to contiaue alive beyond three or four months afterwards. Its death happens from want of nutrition, or in consequence of inflammation of its envelopes."

Another singular feature of my case is this, that the patient carried the dead child for nearly a month; and, that what appeared labour came on at the thirty-eighth woek, er, what is to some romen, the full period of gestation; and, strange to relate, with the usual symptoms of "shor," "grinding" peins, and afterwards "bearing-down" pain "grimding" pean, in his admirahle work on Midwifery, montions the above extraordinary phenomena, and endeavours to account for the same. He says:- "The authors, espocially Tumbull, as well as Cyprianus and Wilmans, mention very remarkable circumstance ; it is, that in these cases, at the close of a kind of labour attended with intermittent pains that are sometimes pretty strong, a commencement of dilatation of the neck, a discharge of mucus, of a bloody fluid, and what seems still more surprising, very regular contractions of the womb, or of the foetal cyst, are observed to take place. In fact, we may conceive a part of these phenomena in tubal pregnancy. The tube being composed of the same elements as the womb, it is quite natural for it to enjoy the same properties; but, in abdominal pregnancy, we can only account for the contraction of the cyst by supposing that there has been a developmont of fleshy fibres in its parietes, at the cost of the elastic cellular layer, which is inclosed in the peritoneum of the pelvis."*

I think that, if the real nature of the case had been ever so clear, we could not hare adopted a different treatment. I wish to call attention to the immense benefit my patient derived from the thorough cleansing of the bowels. If you recollect, the effects were almost magical. Although aporients in this case were most beneficial, opiates were perfectly ineffectual in allaying the pain. With regard to performing the Casarean section, I humbly conceive that we should not have been justified in making an incision into the sbdomen, especially as the child had been dead for a month. Moreover, the previous peritonitis and subsequent bronchitis would have been complete bars to such a rash and daring experiment.

\section{CASE OF POISONING BI OXALIC ACID.}

\section{By T. HERBERT BARKER, M.D., F.R.C.S., Bedford.}

[Read before the Medical Society of London, Nov. 24th, 1855.]

ON 6th October 1855, an inquest was held at Luton, in the county of Bedford, before Ezra Eagles, Esq., coroner for the said county (to whom I am indebted for a perusal of the depositions), touching the death of Thomas Wittocks Willshire; and it appears that there are some points of sufficient interest in this case to warrant the publication of a concise account of it.

It appeared in evidence, that the deceased was only sixteen years old, and lived with his brother at Luton, who had charged him on the 4th instant with abstracting money without his knowledge and consent. This charge the accused at first denied, but afterivards acknowledged to be correct. IIe was of a passionate and revengeful disposition.

After this, the lad procecded at first to Dunstable, and afterwards to the town of Markyate Street, where he purchased one pennyworth of oxalic acid, between seven and eight o'clock in the evening. Between eight and nine o'clock the same evening, he was found lying in a lane, moaning, and with some coloured tluid (as if from romiting) close by him.

Mr. W. A. Hubert, surgeon, of Markyate Street, was passing by the lane at the time he was found, and was called to him. While he was with him, he romited fluid similar to that which was upon the ground. He was insensible, pulseless, and his lower jaw was spasmodically closed. Cold water dashed upon the face restored sensibility, and relaxed the jaw. The boy said that he had taken oxalic acid; that he had eaten it, and did not make any solution; and that his intention was to kill himself, because he had been charged with taking money.

The deceased was carefully conveyed in a cart to his residence in Luton, when Mr. Frederick Clarke, surgeon, of that place, was sent for. He saw him between ten and

* In the quotations from Velpenu's Midwifery, I am indebted to the raluable trauslation of Dr. Meigs.- $\mathrm{T}$. II. c. 